\title{
Operational peculiarities of electric energy meters of different types in power networks with harmonic distortions
}

\author{
Illia Diahovchenko, \\ Ihor Lebedinskyi \\ Department of Electrical Power Engineering, \\ Sumy State University, \\ 2 Rymskogo-Korsakova St., \\ 40007 Sumy, Ukraine \\ Email: ilya.dyagovchenko@gmail.com
}

\begin{abstract}
Electric energy measurements are the base for all commercial electricity transactions. Thus, the validity of the power measurement results is of a great importance. This article studies peculiarities of electric energy accounting in power networks polluted with higher harmonics by means of power meters of various types. It has been demonstrated that the power meters with different operational principles can demonstrate significantly different responses under the same load and network conditions. Consideration of the provisions given in this paper will help to mitigate the measuring uncertainties and reasonably approach the issue of choosing the measuring instruments for billing purposes.
\end{abstract}

Keywords: higher harmonics, power quality, electric energy meters, reactive power, energy measurement

\section{INTRODUCTION}

There are three types of electric energy meters (EEMs) (or power meters) used for power measurement and billing purpose in the Ukrainian low voltage (LV) and medium voltage (MV) power networks, namely inductive (electromechanical), electronic static (analog) and digital. Nowadays, the latter two types of EEMs have almost entirely replaced the traditional but outdated inductive analogues. In Ukraine, electromechanical meters are not anymore installed for billing purposes at new points of electric energy distribution.
The current standards for electricity measurement, specifically EN 62052-11:2003, EN 6205321:2003, EN 50470-1:2006, EN 50470-3:2006, define the requirements that the instruments for both active and reactive energies must comply with nonsinusoidal conditions. The harmonic distortions are only considered for active power meters in EN 62053-21. The manufacturers elaborate the operating principles of the EEMs with the assumption that the network's voltage is sinusoidal or very close to it. However, the real operating conditions of contemporary power networks are usually nonlinear, and the power 
quality (PQ) in the Ukrainian LV and MV networks is often beyond the acceptable thresholds established in the standards EN 50160:2010 and GOST 13109-97 (before the year 2014). In practice, these discrepancies can lead to the situation when calibrated and serviceable EEMs with similar rated values and under the same load parameters demonstrate significantly different readings. In particular, this can be observed when the following types of power measuring instruments are compared: A) electromechanical and static; B) electromechanical and digital; C) two static; D) two digital. The difference in the measurement results of two meters may exceed the sum of their permissible error thresholds.

\section{PREVIOUSLY PUBLISHED WORKS AND THE RESEARCH GOALS}

In the last decades, nonlinear loads generating harmonics are being more frequently connected to the power system. Poor PQ can be caused by industrial or household consumers, who use power converters, arc furnaces, photovoltaic inverters, fluorescent lamps, installations with asymmetric and shock loading, etc. In such a way the revenue meters are subjected to both voltage and current harmonics pollution, while expected to measure electric energy correctly. Several papers are dedicated to the investigation of the influence of nonsinusoidal voltage and current on proper functioning of EEMs [1-8].

In [1], the experiments were carried out for balanced symmetric loading, under artificially generated nonsinusoidal voltages and currents. The laboratory equipment did not record significant uncertainties of the watt-hour meters, instead the measurement errors up to $-35 \%$ were observed for kVA energy meters. In the work [2], the reactive energy measuring devices were tested in real networks with nonsinusoidal voltage. The authors observed deviations in the readings of measuring instruments in the range from $-41 \%$ to $+68 \%$. The common operation principles of contemporary power meters of various types were discussed in [3]. The paper [4] addresses the issues of electric energy measuring in modern power grids, emphasizing the importance of choosing the right components of the distribution measuring system by type, me- trological characteristics, and determining their quantity and location. The requirements applicable to revenue EEMs are discussed in [9]. A conception of the physical mechanism of energy flow in single- and polyphase nonsinusoidal systems with balanced and unbalanced load is given in [5]. The Institute of Electrical and Electronics Engineers (IEEE) has established the methods for determination of active and nonactive power and electric energy in the last revision of its standard IEEE 1459-2010 [6]. The reactive power definitions for billing purposes in LV installations with higher harmonics were analysed, and the most appropriate metric for billing was determined in [7]. A survey of classical and alternative definitions of the power quantities under the presence of higher harmonics is proposed in [10]. The PQ issues, including voltage and frequency fluctuations due to integration of wind turbines and solar photovoltaic $(\mathrm{PV})$ generation, are considered in [11], and the influence of PV-modules on electric energy measurements is estimated in [12].

Despite the practical significance of the previously published results, the influence of the type and operational principles of EEMs on the credibility of their readings was not considered to a sufficient degree. Further research and consideration of these aspects is an actual scientific and technical task, since harmonic distortions and poor PQ can lead to significant errors during the electric energy accounting [8] and cause an increase of commercial (revenue) power losses.

The purpose of this paper is to obtain the theoretical and practical results, which are essential for the adoption/development of optimal operation principles of EEMs to assure the high-accuracy measurement of electric energy in LV and MV networks with harmonic distortions and to minimize the commercial power losses. This work is built on the initial results and analysis presented in $[3,13]$, which are here significantly extended by providing: 1) an additional section with a brief overview of the previous related researches; 2) a more detailed description of the considered operating principles of EEMs; 3 ) additional findings, obtained from the experimental measurements in real field conditions; and 4) a multilateral discussion of the obtained results by analysing them at the light of the issues of metrics and transducers behaviour added. 


\section{ANALYSIS OF THE OPERATION OF ELECTRIC ENERGY METERS IN LOW PQ CONDITIONS}

\section{Instruments of electromechanical type}

The work of the measuring mechanism of an ordinary electromechanical power meter is based on the producing of variable magnetic fluxes of voltage $\Phi_{U}$ and current $\Phi_{I}$ by the shunt electromagnet and the U-shaped series electromagnet. The coil of the U-shaped electromagnet is connected in such a way that it creates magnetic flux $\Phi_{U}$ proportionally to the voltage, and the coil of the shunt electromagnet introduces magnetic flux $\Phi_{I}$ proportionally to the current. The field of the voltage coil is delayed by $90^{\circ}$, due to the coil's inductive nature, and calibrated using a lag coil. This injects eddy currents in the nonmagnetic, but electrically conductive aluminium disc, which rotates at a speed in proportion to the power passing through the EEM. The effect is so that a force is exerted on the disc proportionally to the product of the instantaneous voltage, current and the angle shift between them [14]. The torque of the electromechanical meter can be estimated by the expression

$$
M_{t}=K \cdot \Phi_{U} \cdot \Phi_{I} \cdot \sin \left(90^{\circ}+\varphi\right),
$$

where $K$ is the coefficient, which is determined by the meter's design, and $\varphi$ is the shift angle between voltage and current (power factor).

The coefficient $K$ may vary and is a function of current, voltage and angular frequency: $K=f(U, I, \omega)$. If voltage and current are invariable, then $K$ depends on the angular frequency $\omega$ only [13]. The ratio of the disk speed at the angular frequency of the $n$-th harmonic to the disk speed at the rated angular frequency can be assessed by

$$
K(n)=\frac{K_{n}}{K_{\text {rat }}},
$$

where $K_{n}$ is the value of $K$ for the $n$-th harmonic component, and $K_{r a t}$ is the value of $K$ at the rated angular frequency.

Usually the value $K(n)$ is smaller than the unity when the order of harmonic component $n$ is large. Therefore, the error of the frequency re- sponse of the electromechanical meter is negative when the frequency increases, which is confirmed by the frequency characteristics of such meters obtained in [13]. The $K(n)$ value depends on the meter's parameters, such as voltage braking torque ratio, current braking torque ratio, disk quality factor and voltage coil factor, which are related to the internal structure of the EEM and can be estimated from tests [13].

The error function of the inductive power meter can be calculated by the expression

$$
\delta E \%=100 \sum_{n>1}(K(n)-1) \cdot E(n),
$$

where $E(n)$ is the error coefficient for the $n$-th harmonic component, which is empirically defined and depends on the $n$-th harmonic voltage distortion and current distortion factors [13].

Given that, the expression for active electric energy measured by the inductive meter is

$$
\begin{aligned}
& W_{P}=U_{1} \cdot I_{1} \cdot \cos \varphi_{1} \cdot t \cdot\left(1+\frac{\delta E \%}{100}\right)= \\
& P_{1} \cdot t \cdot\left(1+\frac{\delta E \%}{100}\right) .
\end{aligned}
$$

Given that electromechanical meters of active and reactive energies have a similar structure and alike operating principle, with some approximation the expression for reactive electric energy can be written as

$$
\begin{aligned}
& W_{Q}=U_{1} \cdot I_{1} \cdot \sin \varphi_{1} \cdot t \cdot\left(1+\frac{\delta E \%}{100}\right)= \\
& Q_{1} \cdot t \cdot\left(1+\frac{\delta E \%}{100}\right) .
\end{aligned}
$$

Finding 1. It follows from (4) and (5) that the presence of higher harmonics affects the readings of induction meters of both active and reactive electric energies, and the presence of a constant component of current and/or voltage does not affect their accuracy. In most cases the electromechanical EEM underestimates the electric energy of higher harmonics, and its error has a negative value. This can lead to discrepancies when comparing the readings of EEMs of different types, which refers to the cases A and B listed in the Introduction Section. 


\section{Static instruments for electric energy measurement}

Analog static and digital types of electronic EEMs usually have an input voltage circuit with a precision resistive sensor (voltage divider). There is no electrical isolation at the voltage input, therefore a constant component of the voltage enters the circuit of EEM. Current inputs of static meters are often realized in one of two ways: 1) with the matching current transformer (CT) and 2) with the matching current shunt in the circle of the line conductor [15].

In electric networks with distorted PQ the voltage and current of a complex form are input on the power meters. The root mean square (rms) value of voltage [16] is

$$
U=\sqrt{U_{0}^{2}+U_{1}^{2}+U_{2}^{2}+\ldots+U_{n}^{2}}=\sqrt{\sum_{n=0}^{N} U_{n}^{2}},
$$

where $n$ is the order of the harmonic component, $U_{n}$ is the rms value of the $n$-th harmonic voltage, $U_{0}$ is the voltage constant component, and $N$ is the number of higher harmonics considered.

The rms value of current [16] is

$$
\begin{aligned}
& I=\sqrt{\frac{1}{T} \int_{0}^{T} i^{2} d t}= \\
& \sqrt{I_{0}^{2}+I_{1}^{2}+I_{2}^{2}+\ldots+I_{n}^{2}}=\sqrt{\sum_{n=0}^{N} I_{n}^{2}} .
\end{aligned}
$$

The rms current value excluding the constant component enters the printed circuit board (PCB) of the EEM with CT input:

$$
I=\sqrt{\sum_{n=1}^{N} I_{n}^{2}}
$$

Intrinsically, a Fourier series will only contain no constant component if the mean ordinate of the waveform for the entire period equals zero. The active power of a periodic alternating current of an arbitrary form entering the EEM with a shunt input is calculated as the average power for the entire period. Then the expressions for the active and reactive power can be written as follows:

$$
\begin{aligned}
& P=U_{0} \cdot I_{0} \cdot \cos \varphi_{0}+U_{1} \cdot I_{1} \cdot \cos \varphi_{1}+ \\
& U_{2} \cdot I_{2} \cdot \cos \varphi_{2}+U_{3} \cdot I_{3} \cdot \cos \varphi_{3}+\ldots= \\
& =U_{0} \cdot I_{0}+\sum_{n=1}^{N} U_{n} \cdot I_{n} \cdot \cos \varphi_{n}=P_{0}+\sum_{n=1}^{N} P_{n}, \\
& Q=U_{0} \cdot I_{0} \cdot \sin \varphi_{0}+U_{1} \cdot I_{1} \cdot \sin \varphi_{1}+ \\
& U_{2} \cdot I_{2} \cdot \sin \varphi_{2}+U_{3} \cdot I_{3} \cdot \sin \varphi_{3}+\ldots= \\
& \sum_{n=1}^{N} U_{n} \cdot I_{n} \cdot \sin \varphi_{n}=\sum_{n=1}^{N} Q_{n} .
\end{aligned}
$$

And for the EEMs with CT input:

$$
\begin{aligned}
& P=U_{1} \cdot I_{1} \cdot \cos \varphi_{1}+U_{2} \cdot I_{2} \cdot \cos \varphi_{2}+ \\
& U_{3} \cdot I_{3} \cdot \cos \varphi_{3}+\ldots=\Sigma U_{n} \cdot I_{n} \cdot \cos \varphi_{n}=\sum_{n=1}^{N} P_{n}, \\
& Q=U_{1} \cdot I_{1} \cdot \sin \varphi_{1}+U_{2} \cdot I_{2} \cdot \sin \varphi_{2}+\quad(12) \\
& U_{3} \cdot I_{3} \cdot \sin \varphi_{3}+\ldots=\Sigma U_{n} \cdot I_{n} \cdot \sin \varphi_{n}=\sum_{n=1}^{N} Q_{n} .
\end{aligned}
$$

To determine $P$, the multiplication of the functions represented in the form of electrical signals from the sensors is executed in the measuring microcircuits of static meters, according to expressions (9) and (11). For the measurement of reactive power in accordance with (10) and (12) an additional $90^{\circ}$ phase shift is introduced between the functions of voltage and current. For the rest the measurement of reactive power is like the measurement of active power: EEM multiplies the functions of voltage and current (with a specified $90^{\circ}$ displacement) and finds the function of the instant reactive power. After filtering a value proportionate to the average reactive power $Q$ is obtained.

Finding 2. From (9)-(12) it follows that depending on the presence/absence of the voltage or current constant component, the readings of electronic power meters with different current inputs may mismatch. This explains the differences described in the beginning of the article for electronic static watt-hour meters (case C). It is evidenced from (9) and (11) that the readings of the electronic static active energy meter will exceed the readings of the electromechanical one in all cases. The only exception is when the network's 
voltage and current are ideally sinusoidal. Additionally, for the meters with shunt input there should be no constant component. A similar conclusion for electronic static and electromechanical power meters of reactive energy follows from (10) and (12). These explain the case B, mentioned in the Introduction Section.

It should be noted that when the apparent power is calculated by the formula

$$
S=\sqrt{P^{2}+Q^{2}}
$$

while substituting the quantities calculated from the expressions (9) and (10) or (11) and (12), the result will be different from the actual power value. This difference is explained by the harmonic distortion power, that arises in the networks with nonsinusoidal voltages and currents.

Harmonic distortion power $D_{h}$ represents the degree of difference in voltage and current waveforms. Thus, the apparent power can be defined as [16]

$$
\begin{aligned}
& S=\sqrt{P^{2}+Q^{2}+D_{h}^{2}}= \\
& \sqrt{\begin{array}{l}
\left(\Sigma U_{n} \cdot I_{n} \cdot \cos \varphi_{n}\right)^{2}+\left(\Sigma U_{n} \cdot I_{n} \cdot \sin \varphi_{n}\right)^{2}+ \\
\Sigma\left[U_{k}^{2} I_{n}^{2}+U_{n}^{2} I_{k}^{2}-2 U_{k} I_{k} U_{n} I_{n} \cos \left(\varphi_{k}-\varphi_{n}\right)\right]
\end{array}} .
\end{aligned}
$$

Here the subscripts $k$ and $n$ are independent from each other and take values $1,2,3 \ldots$, but so that $k$ is different from $n$.

The harmonic distortion power is not measurable but can be determined through calculations. It equals zero only if the angle of displacement between the voltage and current for all harmonics is unity, and when the ratios between the effective values of voltage and current for all higher harmonics are the same [3].

The power triangle is widely used as a method to define reactive power in static EEMs:

$$
Q=\sqrt{S^{2}-P^{2}}
$$

When the reactive power is calculated by (15), it is assumed that the apparent power equals the product of the rms values of voltage and current:

$$
S=U I
$$

Finding 3. If the metric (15) is implemented in the static-type reactive power meter, then it takes into account the harmonic distortion power. Thus, even when there is no reactive power consumption on the frequencies of higher harmonics, the measuring instrument may indicate some reactive power consumption. This reaffirms the conclusions for the case A for reactive EEMs.

It should be noted that in the latest revision of IEEE 1459-2010 the quantity in (15) (i.e. the difference in squares of apparent power and active power) is referred as the 'nonactive power', which lumps together both fundamental and nonfundamental nonactive components [6].

\section{Digital instruments for electric energy measurement}

The substantial difference between digital and static power meters is that the electronic circuits of the digital ones are the same for active and reactive energy measuring instruments. In the simplest case their work is realized by means of digital signal processing (DSP), which carries out all necessary conversions by measuring the instantaneous values of current and voltage at discrete time steps. Signals in proportion to the values of current and voltage are obtained from the corresponding sensors and sent to the DSP inputs. The PCB consists of a set of several high-speed analog-to-digital converters of instantaneous values of input currents and voltages.

Properties and measurement uncertainties of digital power meters depend on the metrics embedded in their microprocessors and their features (e.g. the sampling frequency). Generally, all calculation algorithms can be assigned to one of the following two groups [17]: 1) based on the Fourier transform; 2) based on the electrotechnical power definitions.

Let us consider Fourier-transform-based algorithms first. As known, any periodic function $f(x)$, which satisfies the Dirichlet condition (i.e. if it has a finite number of first-of-a-kind breaks during a period and a finite number of maxima and minima), can be introduced as a harmonic series [3]

$$
f(x)=A_{0}+\sum_{k=1}^{\infty}\left(A_{k} \sin k x+B_{k} \cos k x\right),
$$


where the coefficients of the Fourier series are

$$
\begin{aligned}
& A_{0}=\frac{1}{2 \pi} \int_{0}^{2 \pi} f(x) d x \approx \frac{1}{n} \sum_{k=0}^{2 n-1} f_{k}(x)= \\
& \frac{1}{n} \sum_{k=1}^{n} f_{k}(x), \\
& A_{0}=\frac{1}{2 \pi} \int_{0}^{2 \pi} f(x) d x \approx \frac{1}{n} \sum_{k=0}^{2 n-1} f_{k}(x)= \\
& \frac{1}{n} \sum_{k=1}^{n} f_{k}(x), \\
& B_{k}=\frac{1}{2 \pi} \int_{0}^{2 \pi} f(x) \cos k x d x \approx \\
& \frac{2}{n} \sum_{k=1}^{n} f_{k}(x) \cos \left(k m \frac{2 \pi}{n}\right),
\end{aligned}
$$

where $2 n$ is the number of samples of instant magnitudes of voltage or current during the period of the fundamental frequency, $f_{k}(\mathrm{x})$ are states for the instantaneous value of the voltage or current for reference with the numerator $k$, and $m$ is the order of the considered harmonic. Next, current, voltage and power can be calculated in different ways, for example:

- For the fundamental harmonic only the properties of the EEM will be closer to the electromechanical one;

- For several harmonics, excluding the constant component (if there is a current transformer input circuit) - the EEM will be like the electronic static instrument with a CT input;

- For several harmonics, including the constant component (if there is a shunt sensor in the current circuit) - the EEM will be like the electronic static instrument with a shunt input.

Finding 4. It follows from the foregoing that digital electric energy measuring instruments can employ metrics similar to the operating principles of induction and analog static power meters described in the Instruments of electromechanical type and Static instruments Sections. This can serve as an explanation of the case B described in the beginning of the article. Manufacturers are free to apply different metrics of construction of the measuring devices, which are all in accord- ance with the sinusoidal conditions. In most cases, the manufacturers do not declare the implemented metrics, which obstructs the assessment of the metrological characteristics of the power meters. Thus, digital power meters can employ different operating techniques, which can explicate the case D, mentioned in the Introduction Section.

Let us turn to the consideration of algorithms based on the theory of electrical engineering. The value of the active power can be obtained as [17]

$$
P=\frac{1}{T} \sum_{i=0}^{T-1} u_{i} i_{i}=\sum_{k=0}^{N} P_{k},
$$

where $T$ is the number of samples in one period, which is defined as the ratio of the discretization frequency to the network frequency $(50$ or $60 \mathrm{~Hz}$ ), $u_{i}$ and $i_{i}$ are the instantaneous values of voltage and current, respectively, and the active power of $k$-th harmonic is calculated as $P_{k}=U_{k} \cdot I_{k} \cdot \cos \varphi_{k}$.

To obtain the mathematical expression of the reactive power, the current should be shifted by means of a time shifting for a quarter of the period

$$
Q=\frac{1}{T} \int_{0}^{t} u(t) \cdot i\left(t-\frac{T}{4}\right) d t=\sum_{k=0}^{N} Q_{k},
$$

where the reactive power of $k$-th harmonic is found as $Q_{k}=U_{k} \cdot I_{k} \cdot \sin \varphi_{k}$.

Finding 5. It follows from the foregoing and (14) that the calculations by (11) and (21) or by (12), (15) and (22) will give equal results only for purely sinusoidal voltage and current signals without a constant component. The presence of voltage or current distortions or a constant component leads to mismatching readings for EEMs with different operating principles. This once again confirms the possibility of a discrepancy between the readings of power measurement instruments in the case D, mentioned in the Introduction Section.

\section{VERIFICATION OF THE THEORETICAL FINDINGS}

Let us prove the above findings on the example with nonsinusoidal field conditions. The computer room with twenty-one desktops was considered as a load for the test. The compact simulator UCS 500N5 (EM TEST, Switzerland) was set at the input of the test bed to generate the sinusoidal 


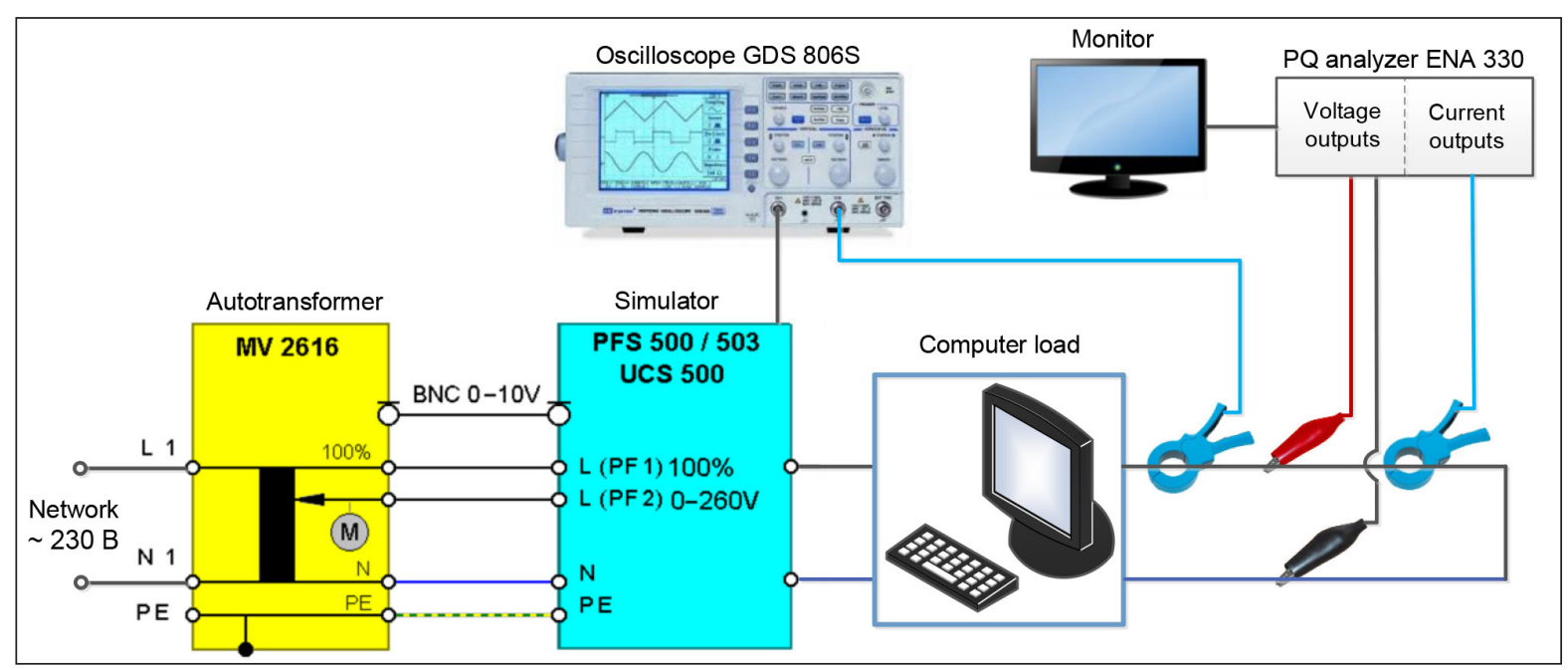

Fig. 1. The block diagram of the laboratory test bed

waveform with the voltage effective value of $230 \mathrm{~V}$ and the frequency of $50 \mathrm{~Hz}$. The autotransformer with the electric drive MV2616 (EM TEST, Switzerland) was used to maintain the desired voltage level and to depress the influence of deviations of voltage supplied from the network. The voltage and current signals were transmitted to the GDS 806S oscilloscope (GW-Instek, Taiwan) for control and visualization purposes. The download of CPUs during the test kept constant and amounted to $70 \%$. The spectra of the harmonics in the voltage and current signals at the output of the computer room were obtained by means of the universal PQ analyzer ENA330 (Elcom Network Analyzer). The block diagram of the laboratory test bed is shown in Fig. 1.

As a result of measurements, the waveforms of voltage (the black curve) and current (the red curve) at the output of the computer room were obtained (Fig. 2), and the harmonics spectrum was

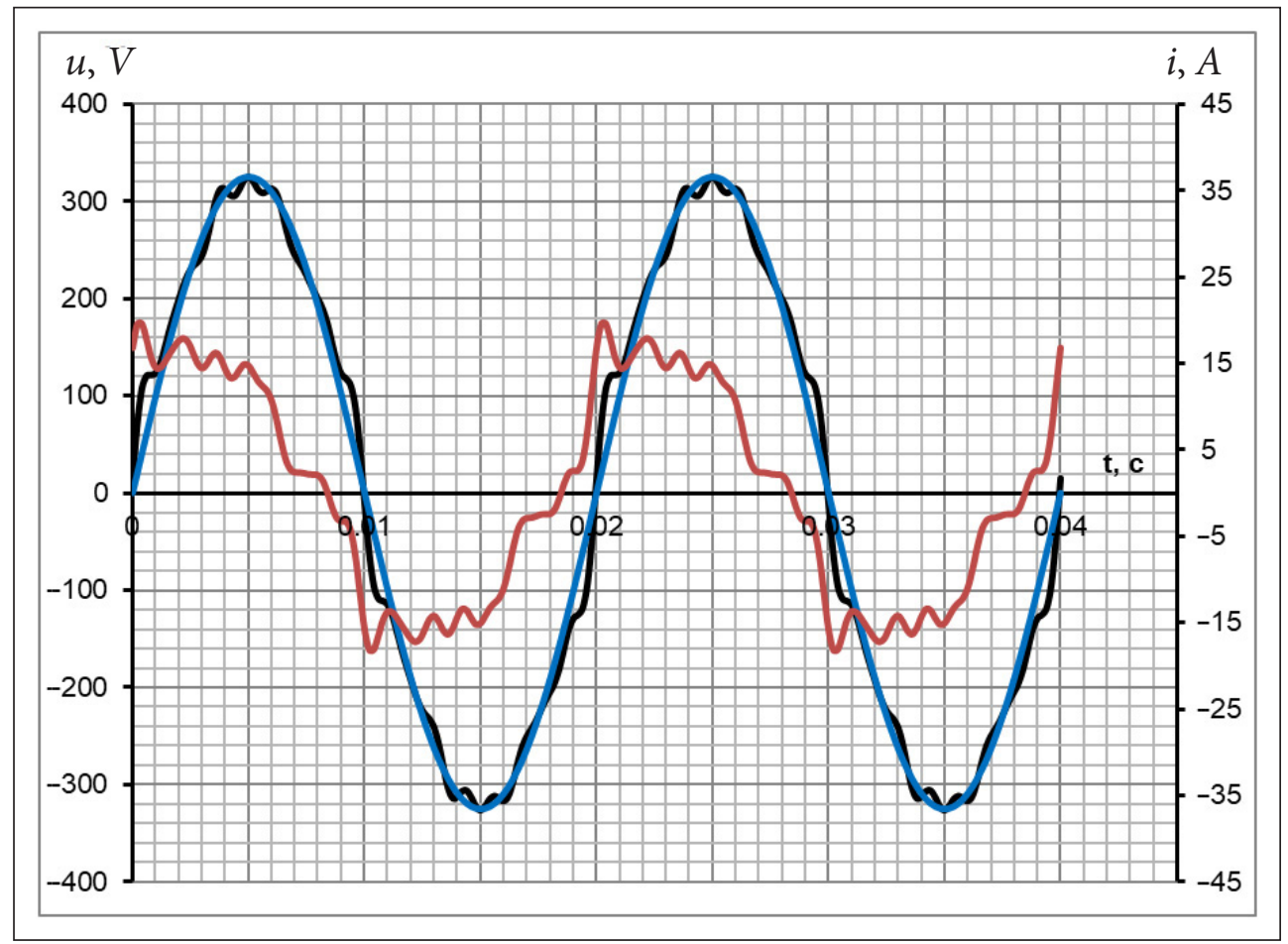

Fig. 2. Instantaneous graphs of voltage $u(t)$ and current $i(t)$ 
defined. The levels of voltage and current total harmonic distortion (THD) for the studied waveforms are as follows: $\mathrm{THD}_{\mathrm{U}}=9.871 \%, \mathrm{THD}_{\mathrm{I}}=16.733 \%$. The values of individual voltage harmonics did not exceed the permissible values set in the EN 50160. The ideal sinusoidal waveform is added in Fig. 2 (the blue curve) for comparison purposes.

The calculated power values for the considered voltage and current waveforms are given in Table 1. The calculations were carried out in accordance with the operating principles of different
EEMs, discussed in the Analysis Section. Note that the electric energy measuring instruments of electromechanical type do not measure the apparent power and, like most electronic meters, do not determine the harmonic distortion power. Therefore, the results in the last three columns of Table 1 are shown for reference only. In Table 1, the apparent powers $S$ and $S^{\prime \prime}$ were assessed by (13) and (16), respectively, and $D_{h}$ was derived from (14).

A graphical representation of the obtained deviations is given in Fig. 3 .

Table 1. The estimated results of power measurement by EEMs with different operating principles

\begin{tabular}{c|c|c|c|c|c|c}
\hline EEM's type & Expression & $\boldsymbol{P}, \mathbf{W}$ & $\mathbf{Q}, \mathbf{V A r}$ & $\boldsymbol{S}^{\prime}, \mathbf{V A}$ & $\boldsymbol{S}^{\prime \prime}, \mathbf{V A}$ & $\boldsymbol{D}_{\boldsymbol{h}^{\prime}}$, VA \\
\hline \multirow{2}{*}{ Electromechanical } & $\begin{array}{c}\text { (4), (5) without } \\
\text { considering } E(n)\end{array}$ & 2197.0544 & 1715.3377 & 2787.3700 & 2787.3700 & $3.0518 \mathrm{E}-05$ \\
\cline { 2 - 7 } & $(4),(5)$ & 2166.6253 & 1690.1534 & 2747.8871 & - & - \\
\hline Static with shunt input & $(9),(10)$ & 2238.9627 & 1743.8594 & 2837.9569 & 2841.7333 & 146.4535 \\
\hline Static with CT input & $(11),(12)$ & 2238.9627 & 1743.8594 & 2837.9569 & 2841.7333 & 146.4535 \\
\hline Digital & $(21),(15)$ & 2238.9627 & 1749.9983 & 2841.7333 & 2841.7333 & $2.16 \mathrm{E}-05$ \\
\hline & $(21),(22)$ & 2238.9627 & 1743.8594 & 2837.9569 & 2841.7333 & 146.4535 \\
\hline $\begin{array}{c}\text { Digital, which defines } \\
\text { power by the fundamen- } \\
\text { tal frequency only }\end{array}$ & $(21),(15)$ & 2197.0544 & 1715.3377 & 2787.3700 & 2787.3700 & $2.1579 \mathrm{E}-05$ \\
\hline $\begin{array}{c}\text { Digital, which defines } \\
\text { power by the first three } \\
\text { harmonics by means of } \\
\text { the Fourier transform }\end{array}$ & $\begin{array}{c}(21),(22) \\
\text { considering } E(n)\end{array}$ & 2197.0544 & 1715.3377 & 2787.3700 & 2787.3700 & $3.0518 \mathrm{E}-05$ \\
\hline
\end{tabular}

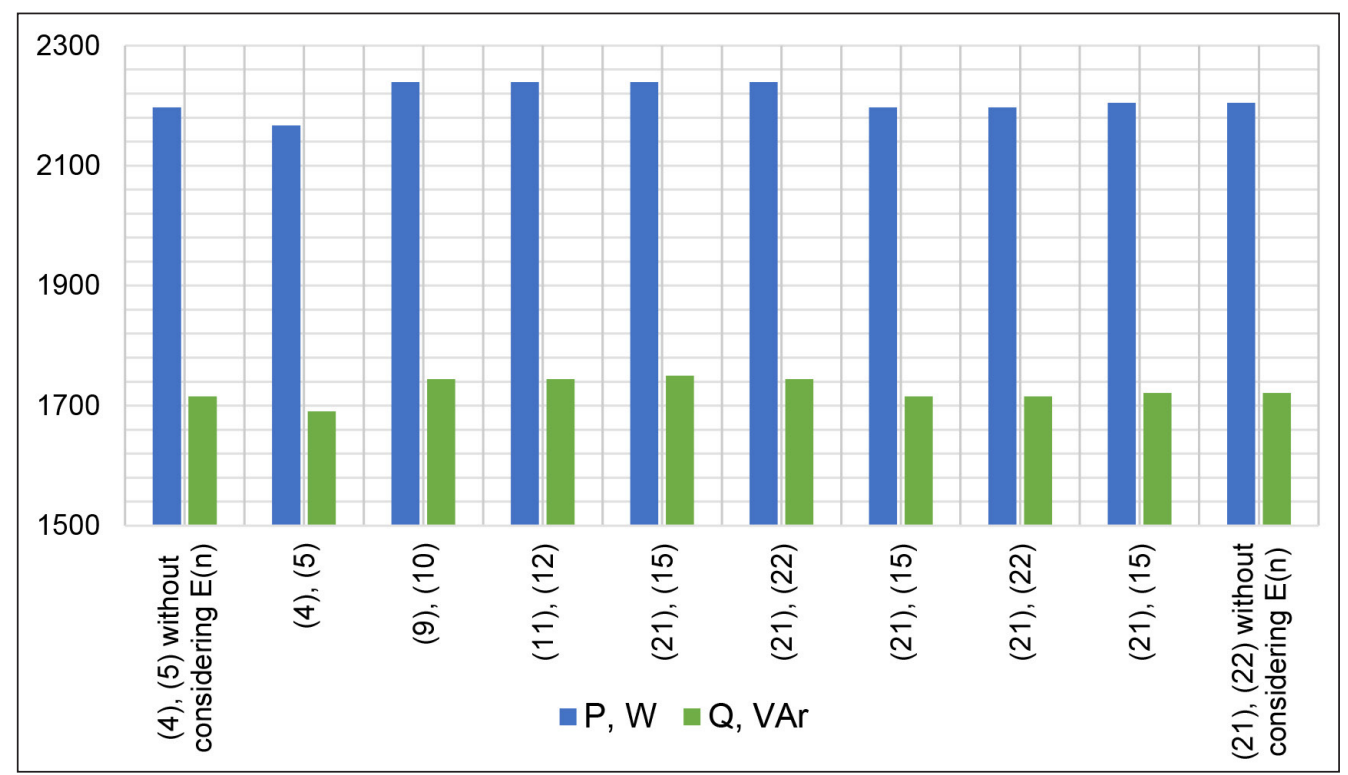

Fig. 3. Deviations in the power measurement results for EEMs with different operating principles 


\section{RESULTS AND DISCUSSION}

According to Table 1, the largest difference between the estimated results of the real power measurements is $3.34 \%$, of the reactive power $3.54 \%$ and of the apparent power $3.42 \%$. From the studied case it is evident that the difference between the readings of EEMs of high metering classes (e.g. classes $0.2 \mathrm{~s}, 0.5 \mathrm{~s}, 1$ defined by the International Electrotechnical Commission (IEC)) may exceed the sum of their permissible errors. At the same time, it should be noted that during the test the values of individual voltage harmonics did not exceed the permissible values established in the standards EN 50160:2010 and GOST 13109-97.

The current standards named in the Introduction Section do not specify the metrological characteristics of the reactive EEMs under the nonsinusoidal conditions. In this situation manufacturers of EEMs are allowed to embed different operating techniques in their products, which all comply with sinusoidal conditions but can lead to measurement of different quantities at the presence of harmonics. Differences in the readings of revenue power meters can violate the unity of the measurement system and bring in substantial errors in the balance of released/received electric energy. When static or most of digital measuring instruments are used for billing purposes, the consumer is forced to pay more for the low-quality electricity due to the presence of higher harmonics. Additional difficulty related to the metrological characterization is that most of the manufacturers do not reveal the operating principles used in their power meters. Thus, no provisions can be made regarding the behaviour of EEM in nonsinusoidal field conditions. The operating technique implemented in a power meter can be identified by the comparison of its response under known field conditions with the calculation results from the known metrics, what is a tedious procedure in terms of required time, equipment and effort.

The appropriate measurement of reactive power using expression (15), which is referred as nonactive power in the IEEE 1459-2010, requires specific methods and a regulatory background that establishes the range of frequency to be taken into account. On the contrast, the val- ue of the fundamental reactive power $Q_{1}$ does not depend on the harmonic distortions of voltage and current. From a measurement point of view, $Q_{1}$ is easily obtained with several simple techniques used in EEMs and its employment for billing purposes will separate the problem of harmonics from the phase difference of voltage and current in the fundamental frequency [7]. The thorough analysis of active and nonactive power components may reveal new information for contemporary EEMs.

In this paper only the measuring discrepancies between the EEMs of different types due to variations in their operating principles are considered. However, in practice additional measuring mismatches may occur due to other factors, such as:

- meters' sampling uncertainties [18];

- meters' frequency responses [13];

- types of the embedded voltage and current transducers $[19,20]$, since different transducers have unlike frequency responses.

\section{CONCLUSIONS}

It is theoretically substantiated and confirmed by experimental measurements and analytical calculations that different EEMs of similar rated values (certified and calibrated), installed in the networks polluted with higher harmonics, can demonstrate a significantly different measuring response at the same load conditions. This can be explained by the following:

- The presence of higher harmonics affects the readings of inductive meters of both active and reactive electric energies, and the presence of a constant component of current and/or voltage does not affect their accuracy.

- The error of the frequency response of the electromechanical meter is negative when the frequency increases. Thus, the electromechanical EEM usually underestimates the electric energy of higher harmonics.

- Static EEM with the current shunt counts both active and reactive energy of higher harmonics, and the active energy of a constant component. Static EEM with the matching current transformer takes into account the power of higher harmonics but is not prone to measure the power created by the existing constant component. 
- Digital measuring instruments can adopt metrics based on the Fourier transformations or on electrical engineering methods for determining power.

- The operating principles embedded in a programmable chip of the electronic power meter are usually not disclosed by the manufacturers.

Received 22 July 2019

Accepted 5 December 2019

\section{References}

1. Arseneau R., Filipski P. S. Application of a three phase nonsinusoidal calibration system for testing energy and demand meters under simulated field conditions. IEEE Transactions on Power Delivery. 1988. Vol. 3. No. 3. P. 874-879.

2. Filipski P. S., Labaj P. W. Evaluation of reactive power meters in the presence of high harmonic distortion. IEEE Transactions on Power Delivery. 1992. Vol. 7. No. 4. P. 1793-1799.

3. Diahovchenko I., Volokhin V., Kurochkina V., Špes M., Kosterec M. Effect of harmonic distortion on electric energy meters of different metrological principles. Frontiers in Energy. 2019. Vol. 13. No. 2. P. 377-385.

4. Muscas C., Pau M., Pegoraro P., Sulis S. Smart electric energy measurements in power distribution grids. IEEE Instrumentation \& Measurement Magazine. 2015. Vol. 18. No. 1. P. 17-21.

5. Emanuel A. E. Power Definitions and the Physical Mechanism of Power Flow. John Wiley \& Sons, Ltd., 2010.

6. IEEE Std 1459-2010 (Revision of IEEE Std 14592000), IEEE Standard Definitions for the Measurement of Electric Power Quantities Under Sinusoidal, Nonsinusoidal, Balanced, or Unbalanced Conditions.

7. Vieira D., Shayani R. A., De Oliveira M. A. G. Reactive power billing under nonsinusoidal conditions for low-voltage systems. IEEE Transactions on Instrumentation and Measurement. 2017. Vol. 66. No. 8. P. 2004-2011.

8. Novotny J., Drapela J., Topolanek D. Frequency response of revenue meters in measured active energy. Proceedings of 2016 17th International Conference on Harmonics and Quality of Power (ICHQP), 2016, Belo Horizonte. P. 524-529.
9. Przydatek P. Regulating Accuracy: Impacts of Changes in ANSI C12.1 and ANSI C12.20. White Paper. Schneider Electric, 2018.

10. Bucci G., Ciancetta F., Fiorucci E., Ometto A. Survey about classical and innovative definitions of the power quantities under nonsinusoidal conditions. International Journal of Emerging Electric Power Systems. 2017. Vol. 18. No. 3. P. 1-16.

11. Liang $X$. Emerging power quality challenges due to integration of renewable energy sources. IEEE Transactions on Industry Applications. 2017. Vol. 53. No. 2. P. 855-866.

12. Volokhin V. V., Diahovchenko I. M., Derevyanko B. V. Electric energy accounting and power quality in electric networks with photovoltaic power stations. Proceedings of 2017 IEEE International Young Scientists Forum on Applied Physics and Engineering (YSF), 2017, Lviv, Ukraine. P. 36-39.

13. Morva G., Volokhin V., Diahovchenko I., Čonka Z. Analysis of the impact of nonlinear distortion in voltage and current curves on the errors of electric energy metering devices. Proceedings of 2017 IEEE 1st Ukraine Conference on Electrical and Computer Engineering, UKRCON 2017, 2017, Kiev, Ukraine. P. 528-533.

14. Facilities Engineering Branch. Whatt-hour Meter Maintenance and Testing. Denver, Colorado: United States Department of the Interior, Bureau of Reclamation, 2000.

15. Volokhin V., Diahovchenko I. Peculiarities of current sensors used in contemporary electric energy metering devices. Energetika. 2017. Vol. 63. No. 1. P. 8-15.

16. Krug K. A. Osnovy elektrotekhniki. Teoriya peremennyh tokov (The Basis of Electrical Engineering. Theory of Alternating Currents). 6th ed. Moscow, Leningrad: Gosudarstvennoe ehnergeticheskoe izdatel'stvo Publ., 1946.

17. Baryshev U. A., Vostroknutov N. N. The basic properties of the errors of modern electricity meters. Kompetentnost. 2015. Vol. 4. P. 42-49.

18. Carstens H., Xia X., Yadavalli S. Measurement uncertainty in energy monitoring: Present state of the art. Renewable and Sustainable Energy Reviews. 2018. Vol. 82. No. 3. P. 2791-2805.

19. Volokhin V. V., Diahovchenko I. M. The use of nanocrystalline and amorphous materials for electric energy metering improvement and 
reducing the effects of external magnetic fields. Proceedings of 2016 International Conference on Nanomaterials: Application \& Properties (NAP), 2016, Lviv, Ukraine. P. 02NEA03-102NEA03-3.

20. Volokhin V. V., Diahovchenko I. M., Derevyanko B. V. Prospects of nanomaterials use in current and voltage hall sensors to improve the measurements accuracy and reduce the external impacts. Proceedings of 2017 IEEE 7th International Conference Nanomaterials: Application \& Properties (NAP), 2017, Odessa, Ukraine. P. 03NE081-03NE08-5.
Illia Diahovchenko, Ihor Lebedinskyi

\section{IVAIRAUS TIPO ELEKTROS ENERGIJOS SKAITIKLIŲ DARBO YPATYBĖS ELEKTROS TINKLE SU AUKŠTOMIS HARMONIKOMIS}

\section{Santrauka}

Elektros energijos matavimai yra visų komercinių elektros sandorių pagrindas, todèl labai svarbus yra šių matavimu pagristumas. Straipsnyje pateikiamos skirtingų tipų elektros energijos skaitiklių darbo ypatybès harmonikomis užterštame elektros tinkle. Tyrimas atskleide, kad su skirtingais veikimo principais pagrịstais elektros skaitikliais galima gauti nevienodus rezultatus, esant tokioms pat apkrovoms ir tokioms pat sąlygoms tinkle. Tyrimo rezultatai padès mažinti elektros apskaitos neapibrěžtumą, ir leis tinkamai pasirinkti elektros skaitiklio tipą.

Raktažodžiai: aukštesniosios harmonikos, elektros kokybe, elektros energijos skaitiklis, reaktyvioji galia, veikimo principai, harmoninis iškraipymas 